\title{
Determination of Catechol and Hydroquinone by Using Perilla frutescens Activated Carbon Modified Glassy Carbon Electrode
}

\author{
Meiqin Zheng, ${ }^{\oplus a}$ Jingjing Zhu, ${ }^{a}$ Rongrong Fan, ${ }^{a}$ Yujie Wang, ${ }^{a}$ Zhaojun Lv, ${ }^{a}$ \\ Yongming Han, ${ }^{a}$ Jun Peng, ${ }^{a}$ Xinyu Zheng ${ }^{*, a, b}$ and Ruiyu Lin ${ }^{* a, b}$ \\ ${ }^{a}$ Fujian Provincial Key Laboratory of Agroecological Processing and Safety Monitoring, \\ College of Life Sciences, 350002 Fuzhou, P. R. China \\ ${ }^{b}$ Key Laboratory of Crop Ecology and Molecular Physiology of Fujian Province University, \\ Fujian Agriculture and Forestry University, 350002 Fuzhou, Fujian, PR China
}

\begin{abstract}
High specific surface area activated carbon prepared by Perilla frutescens (PFHSAAC) was modified on the surface of the glassy carbon electrode (GCE) by drop-coating method to construct a PFHSAAC/GCE. The electrochemical properties of the modified electrode were investigated in detail by some electrochemical methods such as cyclic voltammetry (CV), differential pulse voltammetry (DPV) and electrochemical impedance spectroscopy (EIS). Experiment results show that the modified electrode has excellent redox activity and distinction capability toward the two isomers of catechol (CC) and hydroquinone (HQ). The separation of oxidation peak potential for HQ and CC of DPV is $112.8 \mathrm{mV}$. Under the optimal conditions, the oxidation peak currents of HQ and CC show good linear relationships with their concentrations in the ranges of $1.0 \times 10^{-6}-2.0 \times 10^{-4}$ and $1.0 \times 10^{-6}-1.5 \times 10^{-4} \mathrm{~mol} \mathrm{~L}^{-1}$, respectively. The limits of detection for HQ and $\mathrm{CC}$ are $3.57 \times 10^{-7}$ and $4.23 \times 10^{-7} \mathrm{~mol} \mathrm{~L}^{-1}$, respectively. The PFHSAAC/GCE exhibits good stability, repeatability and sensitivity. The developed method was used to determine HQ and CC in water samples with best results.
\end{abstract}

Keywords: Perilla frutescens, activated carbon, modified electrode, hydroquinone, catechol

\section{Introduction}

As an important pharmaceutical intermediate and basic chemical raw materials, dihydroxybenzene is widely used in the fields of medicines, dye, cosmetics and other related industries. ${ }^{1}$ Due to their high toxicity, catechol (CC) and hydroquinone (HQ) are considered as pollutants to environment and human beings by the US Environmental Protection Agency (EPA). ${ }^{2}$ Thus, it makes sense to search for a rapid, accurate, sensitive and low-cost way for the detection of two dihydroxybenzene isomers. Because of their similar chemical and physical properties, it is difficult to separate and detect CC and HQ simultaneously. Nowadays, due to the advantages of simple operation, high sensitivity, low cost and high reliability, ${ }^{3}$ the electrochemical methods have become a hotspot to determinate dihydroxybenzene isomers simultaneously. ${ }^{4}$ Yet, the oxidation and reduction peaks of HQ and $\mathrm{CC}$ usually overlap together, rendering them unsolvable by conventional electrodes. ${ }^{5}$ According

*e-mail: zhengxinyu 0621@sina.com; lrylin2004@163.com to the reports, some modified electrodes with modifiers comprising polymer, ${ }^{6}$ polyamino acid/carbon, ${ }^{7}$ polyaniline/ graphene,${ }^{8}$ ionic liquid, ${ }^{9}$ porous carbon derived from metal organic frame, ${ }^{10}$ gold nanoparticles-overoxidized polypyrrole-multi-walled carbon nanotubes composite film, ${ }^{11}$ AuNPs/GO@PDA (gold nanoparticles/graphene oxide@ polydopamine $)^{12}$ and activated carbon ${ }^{13}$ have been proposed for the detection of HQ and CC. Among them, carbon materials are widely utilized to enhance the performances of electrochemical sensors. ${ }^{14-19}$

Perilla frutescens (L.) Britt. belonging to an annual herb of the family Labiatae, is widely distributed worldwide, especially in China. Perilla frutescens (L.) Britt. has been confirmed to be able to accumulate and transfer heavy metals. ${ }^{20}$ Our previous studies showed that the enrichment factor of Perilla frutescens (L.) Britt. for $\mathrm{Cd}$ was above $50 .{ }^{21}$ Nevertheless, the disposal of heavy metalsconcentrated plants becomes a bottleneck problem that limits phytoremediation technology.

In this paper, high specific surface area activated carbon prepared by Perilla frutescens (PFHSAAC) was used to 
modify the glassy carbon electrode (GCE). The PFHSAAC was characterized by scanning electron microscopy (SEM) and Brunauer-Emmett-Teller (BET) analysis. The electrochemical properties of PFHSAAC/GCE were studied by using cyclic voltammetry (CV) and electrochemical impedance spectra (EIS). A differential pulse voltammetry (DPV) method was developed for the determination of HQ and CC. These results not only provided a new method for sensitive detection of HQ and $\mathrm{CC}$ in water samples, but also explored a feasible and practical way for reusing the heavy metal enrichment plants.

\section{Experimental}

\section{Reagents and apparatus}

The surface morphology and structure of PFHSAAC were characterized by a scanning electron microscopy (SEM, Hitachi S-4800, Japan). The surface area (calculated by BET method), pore size distribution (calculated by Barrett-Joyner-Halenda (BJH) method) and pore volume were obtained at $77 \mathrm{~K}$ by using three station fully functional multi-purpose gas adsorbent (3Flex, Micromeritics, USA). All electrochemical measurements were performed on a CHI660D electrochemical workstation (Chenhua Instrument Company of Shanghai, China) with a conventional three-electrode system. A platinum wire, a $\mathrm{Ag} / \mathrm{AgCl}$ electrode (in saturated $\mathrm{KCl}$ solution) and a bare GCE or PFHSAAC/GCE (diameter of $3.0 \mathrm{~mm}$ ) were used as the auxiliary electrode, the reference electrode and the working electrode, respectively. All the CV and DPV analysis were taken in $5 \mathrm{~mL}$ of $0.2 \mathrm{~mol} \mathrm{~L}^{-1}$ phosphate buffer solution ( $\mathrm{pH} \mathrm{7)}$ at room temperature. $\mathrm{CC}$ and $\mathrm{HQ}$ were purchased from Aladdin Chemical Co., Ltd. (Shanghai, China). Other chemicals were analytical reagent grade and all solutions were prepared with double distilled deionized water.

\section{Synthesis of activated carbon}

In order to prepare the PFHSAAC, a delicate procedure should be designed. Firstly, in $\mathrm{N}_{2}$ atmosphere, Perilla frutescens powder was placed in a muffle furnace and heated up to $600{ }^{\circ} \mathrm{C}$ at a heating rate of $2{ }^{\circ} \mathrm{C} \mathrm{min}^{-1}$ and held for $1 \mathrm{~h}$. Consequently, the as-pyrolyzed carbon was mixed with $\mathrm{KOH}$ in a mass ratio of 1:4, the mixture was heated at $800{ }^{\circ} \mathrm{C}$ for $1 \mathrm{~h}$ in $\mathrm{N}_{2}$ atmosphere. Finally, the obtained activated carbon was washed by double distilled deionized water and then dried in the drying oven at $120^{\circ} \mathrm{C}$ for $12 \mathrm{~h}$.

\section{Preparation of modified glassy carbon electrode}

A $2.5 \mathrm{mg}$ of PFHSAAC and $1 \mathrm{~mL}$ of $\mathrm{N}, \mathrm{N}$-dimethylformamide (DMF) were mixed ultrasonically for $30 \mathrm{~min}$, and then a uniform and black suspension was obtained. Before modification, GCE was consecutively polished by aqueous alumina slurries with a polishing cloth. Ultrasonic treatment was used to clean the polished electrode in anhydrous ethanol and double distilled deionized water sequentially. At last, definite volume of the suspension was dropped on the surface of GCE and then dried under an infrared lamp.

\section{Results and Discussion}

\section{Characterization of PFHSAAC}

Figure 1 shows the nitrogen adsorption-desorption isotherms and the pore size distribution curve for the PFHSAAC. The prepared PFHSAAC shows type IV curve with hysteresis loop at high pressure, which implies the existence of mesoporous pores. ${ }^{22}$ PFHSAAC possesses a large surface area of $3094.08 \mathrm{~m}^{2} \mathrm{~g}^{-1}$, a large pore volume of $1.65 \mathrm{~cm}^{3} \mathrm{~g}^{-1}$, and a narrow pore-size distribution center at $2.13 \mathrm{~nm}$ (Table 1). The dimension distribution of the aperture belongs to micropore and mesopore. Micropore volume and surface area were accounted for about 5.45 and $6.91 \%$, respectively. These results imply that the porous structure belongs mainly to mesoporous. The large surface area and mesoporous structure promise the potential application of the PFHSAAC in the field of modified electrode. Figure 2 illustrates the surface morphology and structure of PFHSAAC by SEM. It can be seen that the surface of the PFHSAAC contains a large number of pores with different pore diameters. An amorphous structure with a high specific surface area is formed. Such developed pores and high specific surface area can provide channels for the rapid transmission and diffusion of ions. ${ }^{23,24}$ Due to

Table 1. Pore structure parameters of PFHSAAC

\begin{tabular}{lcccc}
\hline $\mathrm{S}_{\mathrm{BET}^{\mathrm{a}}} /\left(\mathrm{m}^{2} \mathrm{~g}^{-1}\right)$ & $\mathrm{V}_{\text {micro }}{ }^{\mathrm{b}} /\left(\mathrm{cm}^{3} \mathrm{~g}^{-1}\right)$ & $\mathrm{V}_{\text {total }}{ }^{\mathrm{d}} /\left(\mathrm{cm}^{3} \mathrm{~g}^{-1}\right)$ & $\mathrm{S}_{\text {micro }}{ }^{\mathrm{d}} /\left(\mathrm{m}^{2} \mathrm{~g}^{-1}\right)$ & $\overline{\mathrm{D}}^{\mathrm{e}} / \mathrm{nm}$ \\
\hline 3094.08 & 0.09 & 1.65 & 213.91 & 2.13 \\
\hline
\end{tabular}

${ }^{a}$ Surface area calculated by Brunauer-Emmett-Teller method; ${ }^{b}$ micropore volume; ${ }^{~}$ total volume; ${ }^{\mathrm{d}}$ micropore surface area; ${ }^{\mathrm{e}}$ mean pore diameter. PFHSAAC: high specific surface area activated carbon prepared by Perilla frutescens. 


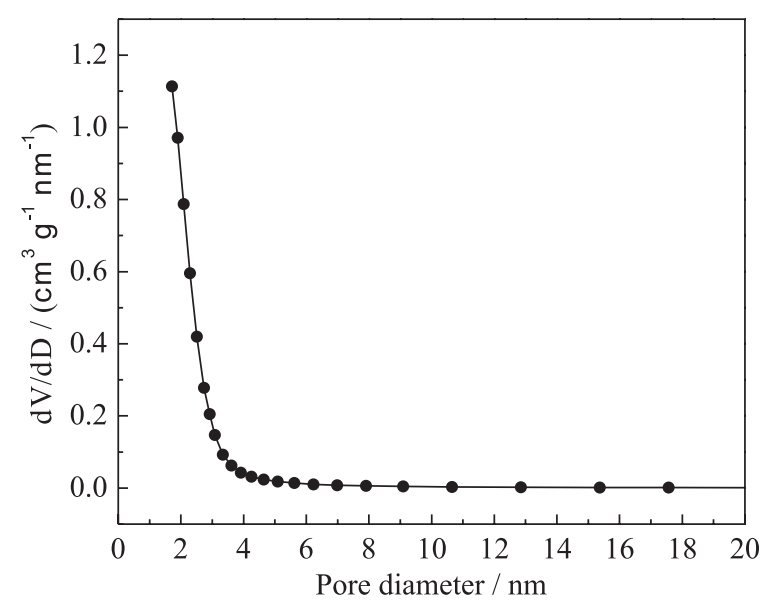

Figure 1. Pore size distribution of PFHSAAC.

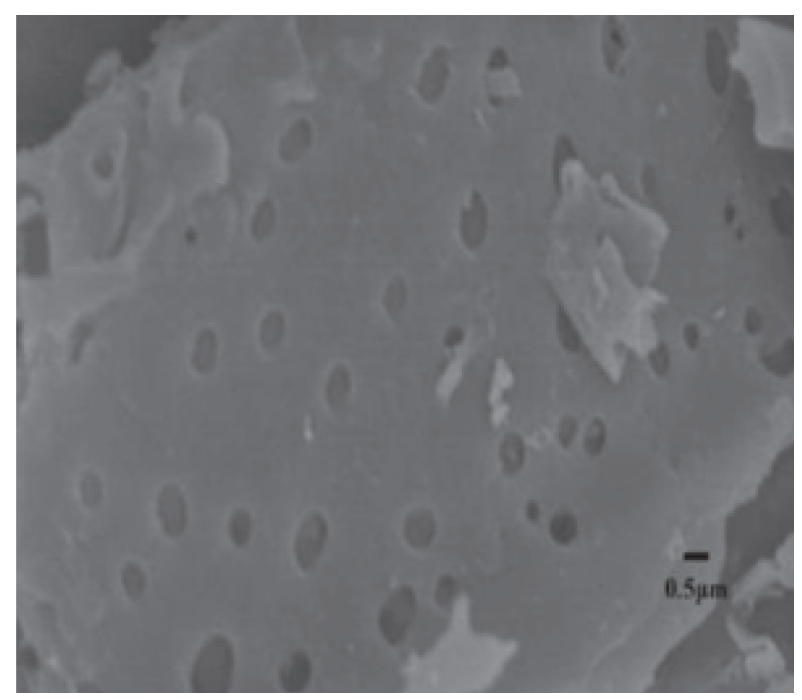

Figure 2. SEM of PFHSAAC.

the structure of the PFHSAAC, a relatively good modified material for electrode can be anticipated.

\section{Performance characterization of modified electrode}

$\mathrm{Fe}(\mathrm{CN})_{6}{ }^{3-14-}$ is always used as an electrochemical probe to evaluate the electrochemical properties of the modified electrode. Figure 3 shows that the redox peak current of $\mathrm{Fe}(\mathrm{CN})_{6}{ }^{3-14}$-remarkably increases and the separation of redox peak potentials $(\triangle \mathrm{Ep})$ for $\mathrm{Fe}(\mathrm{CN})_{6}^{3-/ 4-}$ at the PFHSAAC/GCE is smaller than that of GCE. The oxidation peak current at the PFHSAAC/GCE is 1.5 times as high as that of the GCE. The smaller value of $\triangle \mathrm{Ep}$ and the higher oxidation peak current indicate that the PFHSAAC can increase the reaction area and accelerate the electron transfer process.

According to the Randles-Sevcik equation, ${ }^{25}$ $I_{p}=2.69 \times 105 A^{1 / 2} n^{3 / 2} v^{1 / 2} c$ (where $I_{p}$ is the response current, $\mathrm{A}$ is the effective area of the electrode, D is the diffusion coefficient of the reactant, $\mathrm{n}$ is the electron transfer number of the electrode reaction, $v$ is the scanning speed, and $\mathrm{c}$ is the concentration of the analyte), the surface areas of the PFHSAAC/GCE and GCE can be calculated to be 0.31 and $0.2 \mathrm{~cm}^{2}$, respectively. The active surface area of PFHSAAC/GCE is 1.55 times than that of GCE. According to the view of Hrapovic et al. ${ }^{25}$ and Yang et al. ${ }^{26}$ the larger surface area of the electrode is, the better the electrocatalytic performance and the higher the sensitivity will be. The results further confirm that the PFHSAAC can increase the reaction area and accelerate the electron transfer process.

Electrochemical impedance spectroscopy (EIS) is another method to study the interface features of electrodes in electrochemical reaction. To further investigate the modification of PFHSAAC film on electrode surface, the EIS results of GCE and PFHSAAC/GCE in the presence of equimolar $\left[\mathrm{Fe}(\mathrm{CN})_{6}\right]^{3-14-}$ have been studied, respectively (Figure 4). In order to understand clearly the electrical properties of the electrodes/solution interfaces, the Randles equivalent circuit (inset of Figure 4) was used to fit the obtained impedance data (Table 2), where $\mathrm{R}_{\mathrm{S}}$ is the resistance of the substrate, $\mathrm{C}_{\mathrm{dl}}$ is the electrical double-layer, $\mathrm{R}_{\mathrm{ct}}$ is the charge transfer resistance, and $\mathrm{Z}_{\mathrm{w}}$ is the diffusing resistance of ions from the solution to the interface between the electrode and the solution.

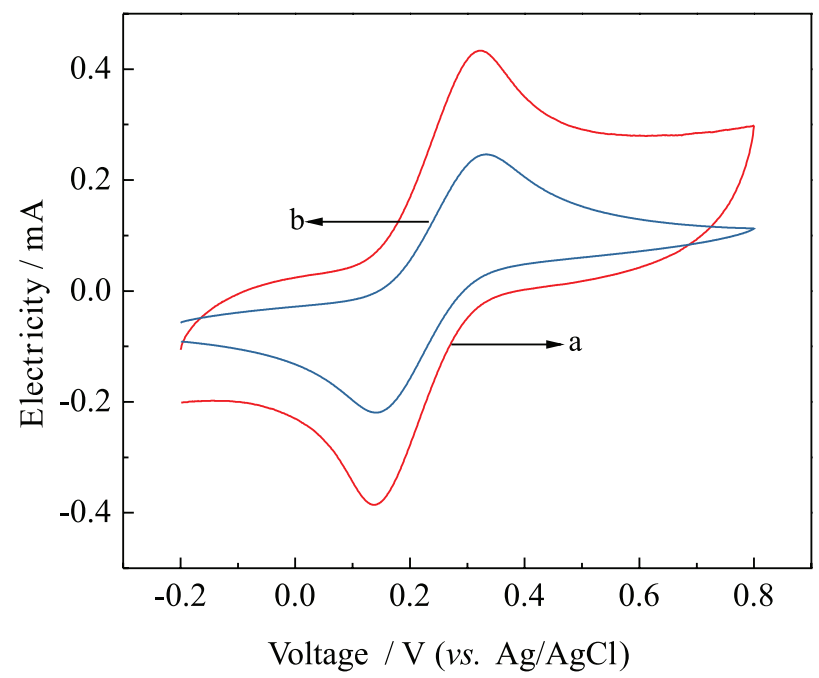

Figure 3. $\mathrm{CV}$ s of PFHSAAC/GCE (curve a) and GCE (curve b) in $5.0 \mathrm{mmol} \mathrm{L}^{-1} \mathrm{~K}_{4}\left[\mathrm{Fe}(\mathrm{CN})_{6}\right] / \mathrm{K}_{3}\left[\mathrm{Fe}(\mathrm{CN})_{6}\right](1: 1)$ solution containing $0.1 \mathrm{~mol} \mathrm{~L}^{-1} \mathrm{KCl}$. Scan rate: $100 \mathrm{mV} \mathrm{s}^{-1}$.

As shown in Figure 4, EIS curve includes a semicircle part and a linear part, the semicircle part at high frequencies corresponds to the electron transfer process, and the linear part at low frequencies corresponds to the diffusion process. ${ }^{27}$ The fitting results indicate the $R_{\mathrm{ct}}$ of the GCE and PFHSAAC/GCE are 622.7 and $75.9 \Omega$, respectively. The $\mathrm{R}_{\mathrm{ct}}$ of the bare electrode is greater than that of the modified electrode, but the $\mathrm{C}_{\mathrm{dl}}$ is smaller, 


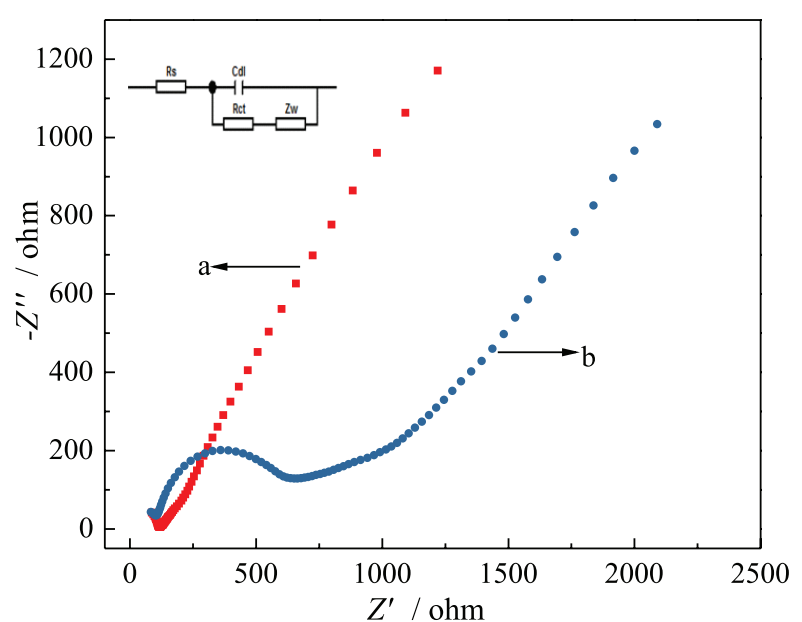

Figure 4. Nyquist plots of EIS in $5.0 \mathrm{mmol} \mathrm{L}^{-1} \mathrm{~K}_{4}\left[\mathrm{Fe}(\mathrm{CN})_{6}\right] / \mathrm{K}_{3}\left[\mathrm{Fe}(\mathrm{CN})_{6}\right]$ (1:1) solution containing $0.1 \mathrm{~mol} \mathrm{~L}^{-1} \mathrm{KCl}$ for PFHSAAC/GCE (curve a) and GCE (curve b). Inset: $R_{S}$ is the resistance of the substrate, $C_{d l}$ is the electrical double-layer, $R_{c t}$ is the charge transfer resistance, and $Z_{w}$ is the diffusing resistance of ions from the solution to the interface between the electrode and the solution.

indicating that the charge transfer speed on the bare electrode is slower. The PFHSAAC builds a good electron channel between the electrode surface and electrolyte. These results agree well with the conclusion of CV.

Table 2. Results for $\mathrm{R}_{\mathrm{ct}}$ and $\mathrm{C}_{\mathrm{dl}}$ obtained after fitting EIS with the equivalent circuit

\begin{tabular}{lcc}
\hline Electrode & GCE & PFHSAAC/GCE \\
\hline $\mathrm{R}_{\mathrm{ct}} / \Omega$ & 622.7 & 75.9 \\
$\mathrm{C}_{\mathrm{dl}} / \mu \mathrm{F}$ & 0.132 & 0.286 \\
\hline
\end{tabular}

$\mathrm{R}_{\mathrm{ct}}$ : charge transfer resistance; $\mathrm{C}_{\mathrm{dl}}$ : electrical double-layer; EIS: electrochemical impedance spectroscopy; GCE: glassy carbon electrode; PFHSAAC: high specific surface area activated carbon prepared by Perilla frutescens.

\section{Electrochemical behavior of $\mathrm{HQ}$ and $\mathrm{CC}$ on modified electrode}

There are a broad oxidation peak and two undistinguished reduction peaks in the $\mathrm{CV}$ (Figure 5, curve b) at bare GCE. The broad oxidation peak can be attributed to the fact that the oxidation peaks of CC and HQ merge into a large peak. This phenomenon manifests that HQ and CC cannot be separated at the bare GCE. On the contrary, distinguishable redox peaks of HQ and CC can be observed in Figure 5 (curve a) at PFHSAAC/GCE. The oxidation peak potentials of HQ and CC are 94.5 and $207.3 \mathrm{mV}$, while the reduction peak potentials are 23.6 and $134.5 \mathrm{mV}$, respectively. The separations of oxidation and reduction peak potential for $\mathrm{HQ}$ and $\mathrm{CC}$ are 112.8 and $110.9 \mathrm{mV}$, respectively. It is reported that $\mathrm{HQ}$ and $\mathrm{CC}$ can be detected separately when the potential difference ranges from 100 to $125 \mathrm{mV}^{28}$ so, it is possible to determine HQ and CC by using PFHSAAC/GCE.

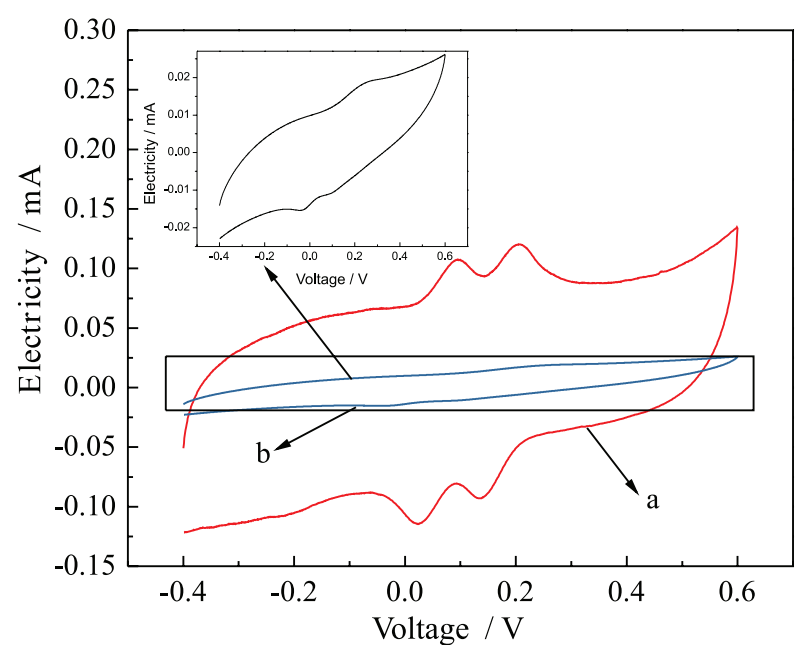

Figure 5. CVs of PFHSAAC/GCE (curve a) and GCE (curve b) in $0.1 \mathrm{mmol} \mathrm{L}{ }^{-1} \mathrm{CC}$ and $0.1 \mathrm{mmol} \mathrm{L}^{-1} \mathrm{HQ}$ solution. Supporting electrolyte: $0.2 \mathrm{~mol} \mathrm{~L}^{-1} \mathrm{NaH}_{2} \mathrm{PO}_{4}-\mathrm{Na}_{2} \mathrm{HPO}_{4}$ buffer solution ( $\mathrm{pH} 7$ ); scan rate: $100 \mathrm{mV} \mathrm{s}^{-1}$.

\section{Electrochemical measurement conditions}

Effect of $\mathrm{pH}$ on the electrochemical behavior of $\mathrm{CC}$ and $\mathrm{HQ}$

Both HQ and CC possess two phenolic hydroxyl groups, ${ }^{7}$ so the acidity of mixed solution to be measured can influence the current responses of HQ and CC. It can be seen that the oxidation peak currents of $\mathrm{CC}$ and HQ increase at first and then decrease with the increase of the $\mathrm{pH}$ value, they reach the maximum when the $\mathrm{pH}$ is 7.0 (Figure 6A). The important reason for this phenomenon may be explained as follow: when the concentration of $\mathrm{H}^{+}$in the solution is higher, the surface of PFHSAAC protonated is more easily and the HQ and $\mathrm{CC}$ are more difficult to be ionized. On the opposite, the two dihydroxybenzene isomers show negative in basic solution, which have an electrostatic repulsion to the negative PFHSAAC. Considering the determination sensitivity, $\mathrm{pH} 7.0$ is chosen as the optimal acidity of the electrolyte. The relationship between the peak potential of two analytes and $\mathrm{pH}$ was also investigated. The results are shown in Figure 6B. It shows that the oxidation peak potentials of $\mathrm{HQ}$ and $\mathrm{CC}$ shift negatively with the increase of the $\mathrm{pH}$ valule. Linear relationships for $\mathrm{HQ}$ and $\mathrm{CC}$ are obtained with the regression equations of $\mathrm{E}_{\mathrm{pa}}(\mathrm{V})=-0.0692 \mathrm{pH}+0.5798(\mathrm{r}=0.9987)$ and $\mathrm{E}_{\mathrm{pa}}(\mathrm{V})=-0.0648 \mathrm{pH}+0.6646(\mathrm{r}=0.9903)$, respectively. The slopes of regression equations are -69.2 and $-64.8 \mathrm{mV} \mathrm{pH}^{-1}$, which are close to the theory value of $58.5 \mathrm{mV} \mathrm{pH}^{-1}$. The results are in agreement with those reported in literature concerned, indicating that the electrochemical redox of CC and HQ at PFHSAAC/GCE should be a two electrons and two protons process. ${ }^{19,29}$ 

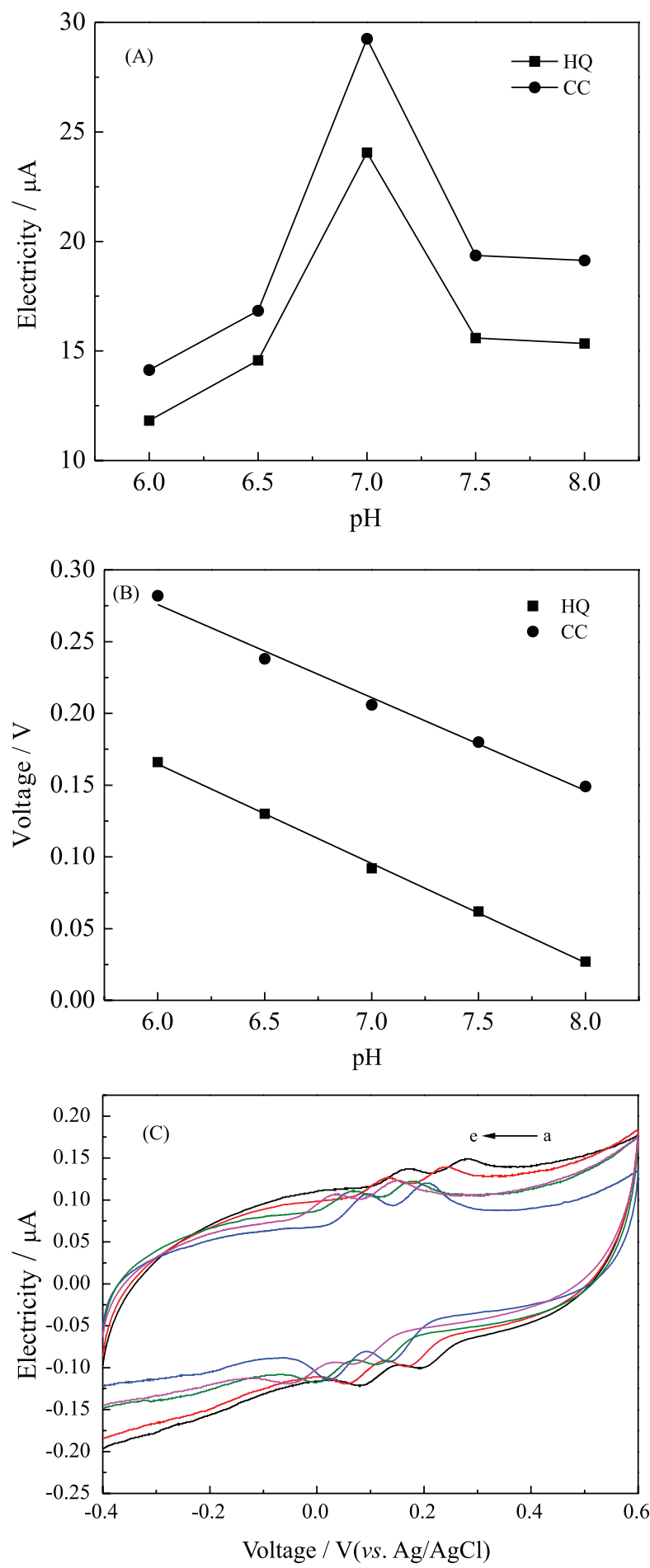

Figure 6. Effects of $\mathrm{pH}$ on the oxidation peak current (A) and oxidation peak potential (B); the CVs of different pHs (from a to e: $6,6.5,7,7.5$, 8) (C) of $0.1 \mathrm{mmol} \mathrm{L}^{-1} \mathrm{HQ}$ and CC. Supporting electrolyte: $0.2 \mathrm{~mol} \mathrm{~L}^{-1}$ $\mathrm{NaH}_{2} \mathrm{PO}_{4}-\mathrm{Na}_{2} \mathrm{HPO}_{4}$ buffer solution ( $\mathrm{pH}$ 7); scan rate: $100 \mathrm{mV} \mathrm{s}^{-1}$.

Effect of scan rate on the electrochemical behavior of CC and $\mathrm{HQ}$

As can be seen in Figure 7, the redox peak currents of $\mathrm{CC}$ and $\mathrm{HQ}$ increase with the scan rates. In the range of 20-100 $\mathrm{mV} \mathrm{s}^{-1}$, the oxidation peak currents are proportional to the scan rates for $\mathrm{CC}$ and HQ. The linear regression equations could be expressed as $I_{p a}(\mu \mathrm{A})=105.3 v+7.778$, $\mathrm{r}=0.9947(\mathrm{HQ})$ and $\mathrm{I}_{\mathrm{pa}}(\mu \mathrm{A})=139.8 v+9, \mathrm{r}=0.9967(\mathrm{CC})$, respectively. The results indicate that the oxidation processes are typical adsorption-controlled processes. ${ }^{29}$ However, in the range of $100-450 \mathrm{mV} \mathrm{s}^{-1}$, the plots of the oxidation peak currents for $\mathrm{CC}$ and $\mathrm{HQ}$ against the square root of scan rate show excellent linear relationships. The linear equations are $\mathrm{I}_{\mathrm{pa}}(\mu \mathrm{A})=35.15 \mathrm{v}^{1 / 2}+4.1073$, $\mathrm{r}=0.9924(\mathrm{HQ})$ and $\mathrm{I}_{\mathrm{pa}}(\mu \mathrm{A})=52.679 \mathrm{v}^{1 / 2}+3.0966$, $\mathrm{r}=0.9951(\mathrm{CC})$, respectively. The results indicate that the oxidation reaction processes of $\mathrm{HQ}$ and $\mathrm{CC}$ on modified electrode surface are diffusion-controlled process. ${ }^{29}$

With the increase of scan rate, the oxidation peak potentials of CC and HQ shift positively and the reduction peak potentials shift negatively. This phenomenon suggests that the reactions for $\mathrm{HQ}$ and $\mathrm{CC}$ are quasi-reversible process. ${ }^{30}$ In this work, the $\mathrm{E}_{\mathrm{pa}}$ and $\mathrm{E}_{\mathrm{pc}}$ are linearly dependent on the natural logarithm of the scan rate (ln v) at the range of $20-450 \mathrm{mV} \mathrm{s}^{-1}$ with the regression equations of $\mathrm{E}_{\mathrm{pa}}(\mathrm{V})=0.0208 \ln \mathrm{v}+0.0149\left(\mathrm{mV} \mathrm{s}^{-1}\right), \mathrm{r}=0.9989$; $\mathrm{E}_{\mathrm{pc}}(\mathrm{V})=0.1163-0.0188 \ln \mathrm{v}\left(\mathrm{mV} \mathrm{s}^{-1}\right), \mathrm{r}=0.9949(\mathrm{HQ})$; $\mathrm{E}_{\mathrm{pa}}(\mathrm{V})=0.0256 \operatorname{ln~} \mathrm{v}+0.1059\left(\mathrm{mV} \mathrm{s}^{-1}\right), \mathrm{r}=0.9947$; $\mathrm{E}_{\mathrm{pc}}(\mathrm{V})=0.2126-0.0161 \ln \mathrm{v}\left(\mathrm{mV} \mathrm{s}^{-1}\right), \mathrm{r}=0.997(\mathrm{CC})$.

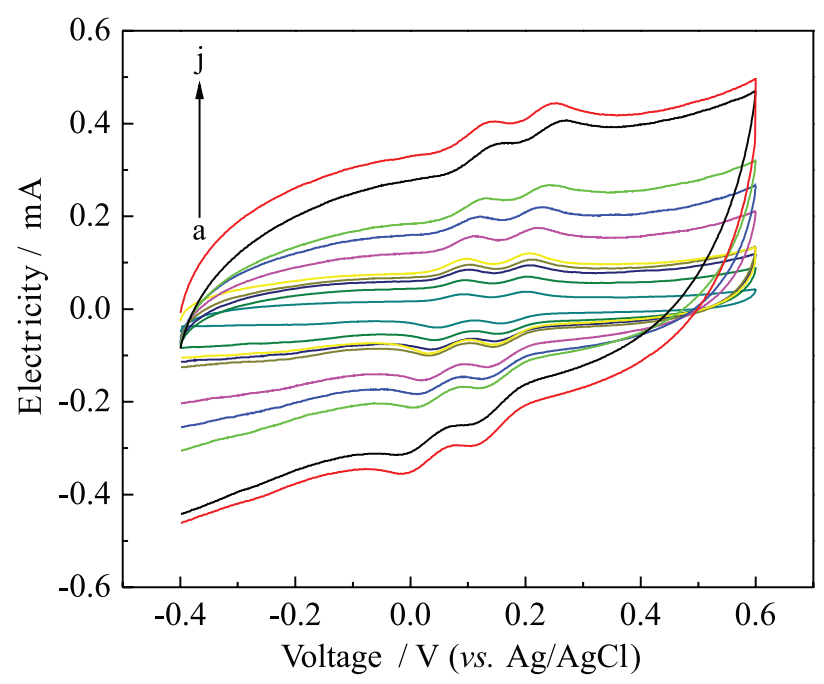

Figure 7. CVs of the PFHSAAC/GCE in $0.2 \mathrm{~mol} \mathrm{~L}^{-1} \mathrm{NaH}_{2} \mathrm{PO}_{4}-\mathrm{Na}_{2} \mathrm{HPO}_{4}$ containing $1 \times 10^{-4} \mathrm{~mol} \mathrm{~L}^{-1} \mathrm{HQ}$ and $\mathrm{CC}$ buffer solution $(\mathrm{pH} 7.0)$ at various scan rates. Scan rate (from a to j): 20, 40, 60, 80, 100, 150, 200, 250, $350,450 \mathrm{mV} \mathrm{s}^{-1}$.

Influence of different amounts of the PFHSAAC on the current responses of $\mathrm{HQ}$ and $\mathrm{CC}$

Influences of different amounts of the PFHSAAC on the current responses of $\mathrm{HQ}$ and $\mathrm{CC}$ were well investigated. The current responses of HQ and CC enhance gradually to a maximum value and then decrease with the increase 


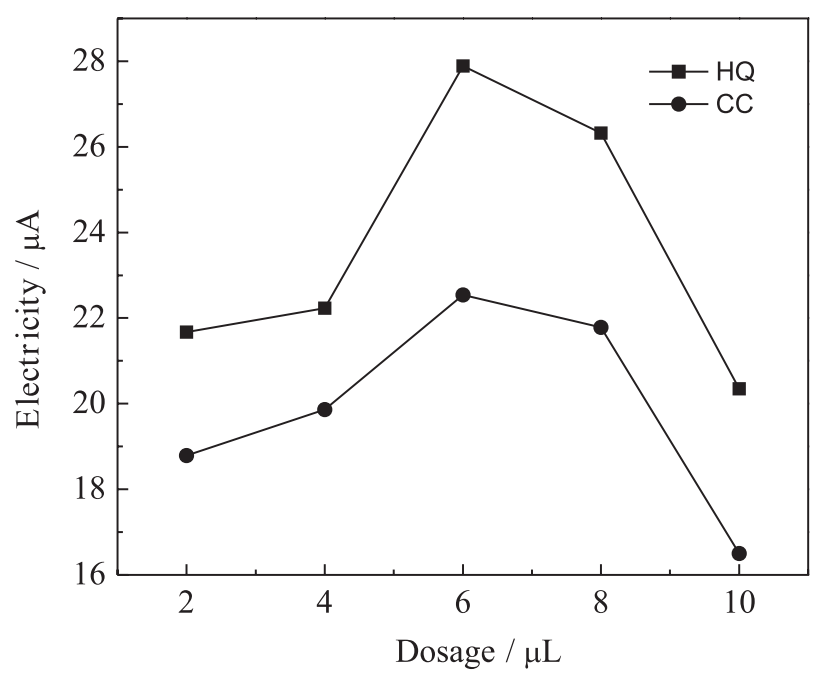

Figure 8. Effect of the amount of dispersion on the current responses of $1 \times 10^{-4} \mathrm{~mol} \mathrm{~L}^{-1} \mathrm{CC}$ and $\mathrm{HQ}$ in $0.2 \mathrm{~mol} \mathrm{~L}^{-1} \mathrm{NaH}_{2} \mathrm{PO}_{4}-\mathrm{Na}_{2} \mathrm{HPO}_{4}$ buffer solution ( $\mathrm{pH} 7.0)$.

volume of the suspension of PFHSAAC. As can be shown in Figure 8, the maximum response currents of $\mathrm{HQ}$ and $\mathrm{CC}$ occur when the volume is $6 \mu \mathrm{L}$. So, $6 \mu \mathrm{L}$ were chosen as the optimal amounts of the suspension.

Determination of $\mathrm{CC}$ and $\mathrm{HQ}$ with differential pulse voltammetry

Considering the detection of sensitivity and accuracy, the determination of $\mathrm{HQ}$ and $\mathrm{CC}$ at PFHSAAC/GCE were carried out by DPV method under optimum conditions. As shown in Figure 9, the peak current of HQ increasing linearly with the increasing concentration. However, the changes of HQ concentration have no significant influence on the peak currents and peak potentials of CC. Similarly,

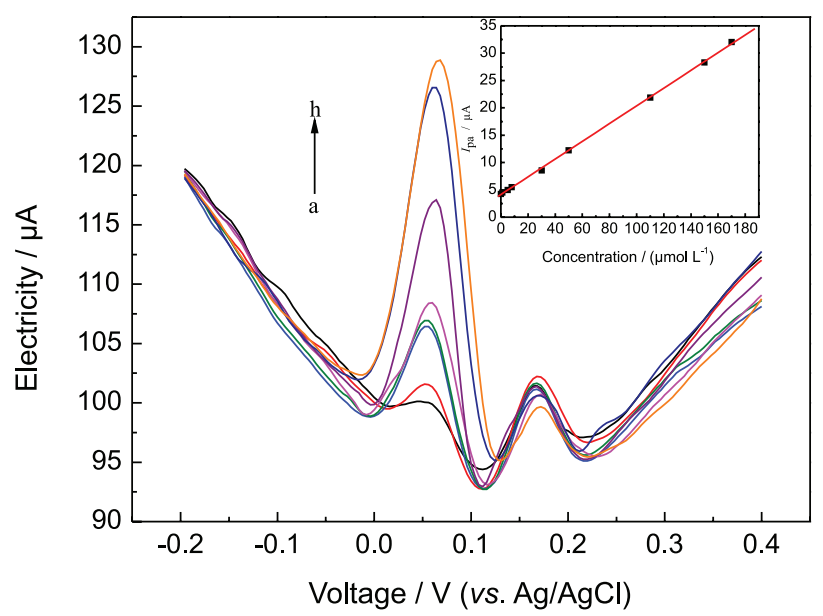

Figure 9. DPVs of $\mathrm{HQ}$ at the PFHSAAC/GCE in the presence of $2 \times 10^{-5} \mathrm{~mol} \mathrm{~L}^{-1} \mathrm{CC}$ in $0.2 \mathrm{~mol} \mathrm{~L} \mathrm{~L}^{-1} \mathrm{NaH}_{2} \mathrm{PO}_{4}-\mathrm{Na}_{2} \mathrm{HPO}_{4}$ buffer solution (pH 7.0). HQ concentrations (from a to h) / $\mathrm{mol} \mathrm{L}^{-1}: 1 \times 10^{-6}, 5 \times 10^{-6}$, $8 \times 10^{-6}, 3 \times 10^{-5}, 5 \times 10^{-5}, 1.1 \times 10^{-4}, 1.5 \times 10^{-4}$ and $1.7 \times 10^{-4}$. as shown in Figure 10, the linear relationship between the oxidation peak current and solution concentration of CC can also be achieved. The corresponding linear functions are $\mathrm{I}_{\mathrm{pa}}(\mu \mathrm{A})=0.1584 \mathrm{c}\left(\mu \mathrm{mol} \mathrm{L}^{-1}\right)+4.25, \mathrm{r}=0.9920(\mathrm{HQ})$ and $\mathrm{I}_{\mathrm{pa}}(\mu \mathrm{A})=0.314 \mathrm{c}\left(\mu \mathrm{mol} \mathrm{L} \mathrm{L}^{-1}\right)+3.6479, \mathrm{r}=0.9917(\mathrm{CC})$, respectively. The limits of detection for $\mathrm{HQ}$ and $\mathrm{CC}$ are 0.357 and $0.423 \mu \mathrm{mol} \mathrm{L}^{-1}$, respectively. A comparison of the proposed method with other electrochemical methods is listed in Table 3. It indicates that the prepared PFHSAAC has good application prospects in the field of modified electrodes.

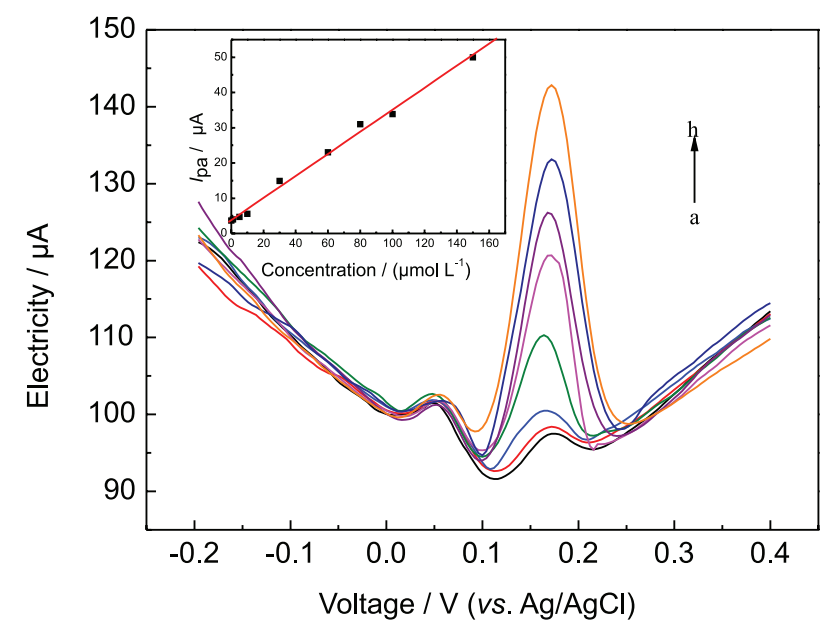

Figure 10. DPVs of $\mathrm{CC}$ at the PFHSAAC/GCE in the presence of $2 \times 10^{-5} \mathrm{~mol} \mathrm{~L}-1 \mathrm{HQ}$ in $0.2 \mathrm{~mol} \mathrm{~L}-1 \mathrm{NaH}_{2} \mathrm{PO}_{4}-\mathrm{Na}_{2} \mathrm{HPO}_{4}$ buffer solution (pH 7.0). CC concentrations from a to $\mathrm{h} /\left(\mathrm{mol} \mathrm{L}^{-1}\right): 1 \times 10^{-6}, 5 \times 10^{-6}$, $1 \times 10^{-5}, 3 \times 10^{-5}, 6 \times 10^{-5}, 8 \times 10^{-5}, 1 \times 10^{-4}$ and $1.5 \times 10^{-4}$.

Reproducibility stability and interference studies

Under the optimal conditions, the reproducibility of the PFHSAAC/GCE was examined by DPV for seven consecutive measurements in phosphate buffer solution (pH 7.0) containing $100 \mu \mathrm{mol} \mathrm{L}^{-1} \mathrm{HQ}$ and $100 \mu \mathrm{mol} \mathrm{L}^{-1} \mathrm{CC}$. The relative standard deviation (RSD) of the oxidation currents of both HQ and CC are calculated to be 4.1 and $2.7 \%$, respectively. After cleaning and drying, the electrode was stored in phosphate buffer solution ( $\mathrm{pH}$ 7.0) for three weeks at $4{ }^{\circ} \mathrm{C}$ in a refrigerator. The peak currents of HQ and $\mathrm{CC}$ remain $92.8(\mathrm{SD}=3.2 \%)$ and $94.1 \%(\mathrm{SD}=1.8 \%)$, respectively. The results suggest the PFHSAAC/GCE has a high stability. In order to evaluate some possible influence factors, some common ions such as $\mathrm{Mg}^{2+}, \mathrm{Na}^{+}$, $\mathrm{K}^{+}, \mathrm{NH}_{4}{ }^{+}, \mathrm{SO}_{4}{ }^{2-}, \mathrm{NO}_{3}{ }^{-}, \mathrm{Cl}^{-}$and $\mathrm{CO}_{3}{ }^{2-}$ were added to $0.2 \mathrm{~mol} \mathrm{~L}^{-1}$ phosphate buffer solution $(\mathrm{pH} 7.0)$ containing $100 \mu \mathrm{mol} \mathrm{L}{ }^{-1} \mathrm{HQ}$ and $100 \mu \mathrm{mol} \mathrm{L}^{-1} \mathrm{CC}$. The concentrations of interfering ions are 100 times of HQ and CC. No remarkable interferences can be observed. Under the same condition, some structurally similar substances, such as 
Table 3. Performance comparison of the fabricated electrode for HQ and CC detection with other electrodes

\begin{tabular}{|c|c|c|c|c|c|}
\hline \multirow[b]{2}{*}{ Modifier } & \multicolumn{2}{|c|}{ HQ } & \multicolumn{2}{|c|}{$\mathrm{CC}$} & \multirow[b]{2}{*}{ Reference } \\
\hline & $\begin{array}{l}\text { Linear range / } \\
\left(\mu \mathrm{mol} \mathrm{L} \mathrm{L}^{-1}\right)\end{array}$ & $\begin{array}{l}\text { Limit of detection / } \\
\qquad\left(\mu \mathrm{mol} \mathrm{L} \mathrm{L}^{-1}\right)\end{array}$ & $\begin{array}{c}\text { Linear range / } \\
\left.(\mu \mathrm{mol} \mathrm{L})^{-1}\right)\end{array}$ & $\begin{array}{l}\text { Limit of detection / } \\
(\mu \mathrm{mol} \mathrm{L}-1)\end{array}$ & \\
\hline Activated carbon & $1-200$ & 0.357 & $1-150$ & 0.423 & this work \\
\hline Polyaniline-graphene & $1-800$ & 0.1 & $1-800$ & 0.08 & 8 \\
\hline AuNPs-OPPy-MWCNTs & $0.2-100$ & 0.06 & $0.2-100$ & 0.08 & 11 \\
\hline Fluorinated graphite & $1-150$ & 0.43 & $1-150$ & 0.31 & 31 \\
\hline PGCE & $10-300$ & 3.57 & $10-300$ & 3.99 & 32 \\
\hline L-Histidine-erythrosine & $1.2-110$ & 0.19 & $1.2-110$ & 0.16 & 33 \\
\hline Composite film & $5-100$ & 0.3 & $1-75$ & 0.2 & 34 \\
\hline Boron-doped graphene & $0.5-465$ & 0.1 & $0.2-80$ & 0.06 & 35 \\
\hline $\mathrm{PANi}^{-\mathrm{Fe}_{2}} \mathrm{O}_{3}-\mathrm{rGO}$ & $1-10$ & 0.18 & 1-10 & 0.26 & 36 \\
\hline CRGO & 3-137 & 1.1 & $2-145$ & 0.8 & 37 \\
\hline 3DFG & $0.31-13.1$ & 0.1 & $0.25-13$ & 0.08 & 38 \\
\hline
\end{tabular}

HQ: hydroquinone; CC: catechol; AuNPs-OPPy-MWCNTs: gold nanoparticles-overoxidized polypyrrole-multi-walled carbon nanotubes composite film; PGCE: cathode polarized GCE; $\mathrm{PANi}-\mathrm{Fe}_{2} \mathrm{O}_{3}$-rGO: polyaniline nanofiber incorporated into iron oxide-reduced graphene oxide; CRGO: chemically reduced graphene oxide; 3DFG: three-dimensional functionalized graphene.

bisphenol A, $o$-nitrophenol and $p$-nitrophenol have hardly any influences on benzodiazepines.

\section{Real sample analysis}

In order to assess the possible applications of the proposed method, the determination of CC and HQ in local lake water was performed. The water samples were diluted with phosphate buffer solution. They were measured by the standard addition method. The results are shown in Table 4. It is noted that the recoveries of HQ and CC are 90.8-99.4 and 91.2-111.2\%, respectively, indicating that PFHSAAC/GCE has promising application and reliability for determination of $\mathrm{HQ}$ and $\mathrm{CC}$ in the environmental samples.

The method was validated by analysis of HQ and CC in water samples by the standard HPLC method. ${ }^{39}$ Good agreement in terms of accuracy and precision were achieved for the analysis of HQ and CC in the water sample by the developed method and standard high performance liquid chromatography (HPLC) method as given in Table 5. The experimental $t$ (1.98 and 1.78) and $F$ values (2.85 and 5.08$)$ at $95 \%$ confidence $(\mathrm{n}=5)$ do not exceed the theoretical $t$ (2.31) and $F(6.39)$ values, respectively. These results confirmed that the developed method is accurate.

\section{Conclusions}

In this work, a sensitive and reliable electrochemical platform was designed. The electrochemical behavior of $\mathrm{CC}$ and HQ was investigated with PFHSAAC/GCE by $\mathrm{CV}$ and DPV methods. Compared with the bare GCE, the modified electrode exhibit high electrocatalytic activity,

Table 4. Recoveries of catechol and hydroquinone in imtative water samples

\begin{tabular}{lccc}
\hline Test project & Adding standard $/\left(\mu \mathrm{mol} \mathrm{L}{ }^{-1}\right)$ & Measured quantity / $\left(\mu \mathrm{mol} \mathrm{L}^{-1}\right)$ & Adding standard recovery / \% \\
\hline \multirow{2}{*}{ HQ } & 5.00 & 4.97 & 99.4 \\
\hline \multirow{2}{*}{ CC } & 50.0 & 45.4 & 90.8 \\
& 5.0 & 5.56 & 111.2 \\
\hline
\end{tabular}

HQ: hydroquinone; CC: catechol.

Table 5. Analysis of HQ and CC in water samples by the modified electrode and the HPLC methods

\begin{tabular}{|c|c|c|c|c|c|c|}
\hline \multirow{2}{*}{ Detection object } & \multicolumn{2}{|c|}{$\begin{array}{l}\text { Adding standard / } \\
\left(\times 10^{-5} \mathrm{~mol} \mathrm{~L}^{-1}\right)\end{array}$} & \multicolumn{2}{|c|}{$\begin{array}{l}\text { Measured quantity / } \\
\left(\times 10^{-5} \mathrm{~mol} \mathrm{~L}^{-1}\right)\end{array}$} & \multirow{2}{*}{$\begin{array}{c}t_{\text {calculated }}{ }^{\mathrm{a}} \\
\left(t_{\text {referenced }}=2.31\right)\end{array}$} & \multirow{2}{*}{$\begin{array}{c}F_{\text {calculated }} \mathrm{b} \\
\left(F_{\text {referenced }}=6.39\right)\end{array}$} \\
\hline & $\mathrm{A}$ & $\mathrm{B}$ & $\mathrm{A}$ & $\mathrm{B}$ & & \\
\hline HQ & 0.500 & 0.500 & $0.503 \pm 0.027$ & $0.520 \pm 0.016$ & 1.98 & 2.85 \\
\hline $\mathrm{CC}$ & 0.500 & 0.500 & $0.514 \pm 0.016$ & $0.506 \pm 0.007$ & 1.78 & 5.08 \\
\hline
\end{tabular}

${ }^{a}$ Experimental Student's $t$ values at 95\% confidence; ${ }^{b}$ Fisher $F$-test values at 95\% confidence. A: modified electrode; B: HPLC: high performance liquid chromatography; HQ: hydroquinone; CC: catechol. 
which can be attributed to the large specific surface. The proposed method was applied to determine CC and HQ in real samples with satisfactory results. The high sensitivity, excellent selectivity, good reproducibility, as well as long stability make it a promising candidate for designing effective dihydroxybenzene sensor.

\section{Acknowledgments}

The authors are grateful to the support of the National Key Research and Development Program of China (2017YFD0800900), National Science and Technology basic Project of the Ministry of Science and Technology of China (2015FY3260051), the Scientific Research Fund of Natural Science Foundation of Fujian Province (2015J01081, 2013J01083) and the Opening Foundation of National Engineering Research Center for Sugarcane (PTJH1500114).

\section{References}

1. He, J. H.; Qiu, R.; Li, W. P.; Xing, S. H.; Song, Z. R.; Li, Q.; Zhang, S. T.; Anal. Methods 2014, 66, 494.

2. Yuan,X.L.;Yuan, D. S.;Zeng, F.L.;Zou, W.J.; Tzorbatzogloub,F.; Tsiakaras, P.; Wang, Y.; Appl. Catal., B 2013, 129, 367.

3. Prathap Anu, M. U.; Satpati, B.; Srivastava, R.; Sens. Actuators, B 2013, 186, 67.

4. Li, S. J.; Qian, C.; Wang, K.; Hua, B. Y.; Wang, F. B.; Sheng, Z. H.; Xia, X. H.; Sens. Actuators, B 2012, 174, 441.

5. Wang, C. Y.; You, T. Y.; Tian, J.; Chinese J. Anal. Chem. 2011, $39,528$.

6. Silva, P. S.; Gasparini, B. C.; Magosso, H. A.; Spinelli, A.; J. Braz. Chem. Soc. 2013, 24, 695.

7. Guo, Y. H.; Wang, H. D.; Xu, R. X.; Chen, S.; Li, Q. L.; Zheng, X. Y.; J. Instrum. Anal. 2014, 33, 318.

8. Zhai, J. L.; Hao, J. X.; J. Anal. Sci. 2015, 31, 384.

9. Wang, X.; Wu, M.; Li, H.; Wang, Q. J.; He, P. G.; Fang, Y. Z.; Sens. Actuators, B 2014, 192, 452.

10. Wu, Y. J.; Zhou, H. F.; Li, S. X.; J. Anal. Sci. 2017, 33, 11.

11. Yu, H.; Xu, N.; Gao, X. L.; Jin, J.; Chinese J. Anal. Chem. 2016, 44, 1077.

12. Palanisamy, S.; Thangavelu, K.; Chen, S. M.; Thirumalraj, B.; Liu, X. H.; Sens. Actuators, B 2016, 233, 298.

13. Zuo, S. L.; Cai, X.; Yin, Y. S.; J. Nanjing For. Univ., Nat. Sci. Ed. 2010, 34, 133.

14. Wu, Y. T.; Wu, L.; Xia, M. Z.; Wang, F. Y.; Li, C. W.; Zhang, C.; Hao, Q. L.; Zhang, Y. H.; Appl. Clay Sci. 2018, 162, 38.

15. Erogul, S.; Bas, S. Z.; Ozmen, M.; Yildiz, S.; Electrochim. Acta 2015, 186, 302.

16. Zhang, H. S.; Bo, X. J.; Guo, L. P.; Sens. Actuators, B 2015, 220, 919.
17. Wei, C.; Huang, Q. T.; Hu, S. R.; Zhang, H. Q.; Zhang, W. X.; Wang, Z. M.; Zhu, M. L.; Dai, P. W.; Huang, L. Z.; Electrochim. Acta 2014, 149, 237.

18. Cui, Y. P.; Zhu, Y.; Li, Y. L.; Wang, W. X.; Xu, F.; Res. Chem. Intermed. 2014, 40, 3153.

19. Liu, W.; Wu, L.; Zhang, X. H.; Chen, J. H.; Bull. Korean Chem. Soc. 2014, 35, 1204.

20. Liu, X.; Zhang, S. R.; Zhu, R.; Xu, X. X.; Fan, X. W.; J. AgroEnviron. Sci. 2009, 28, 2264.

21. Xie, H. L.; Chen, A. P.; Zhang, F. Y.; Xiong, Y.; Chen, Y. L.; Liu, J.; Zhou, L. Y.; Lin, R. Y.; Chin. J. Eco-Agric. 2011, 19, 672.

22. Xing, X. J.; Sun, Z. K.; Fan, F. Y.; Ma, P. Y.; Zhang, X. W.; Yu, J.; Wu, Z. B.; CIESC J. 2016, 67, 2638.

23. Xing, B. L.; Guo, H.; Chen, L. J.; Chen, Z. F.; Zhang, C. X.; Huang, G. X.; Xie, W.; Yu, J. L.; Fuel Process Technol. 2015, $138,734$.

24. Huang, J. Y.; Chen, L. D.; Dong, H. W.; Zeng, Y.; Hu, H.; Zheng, M. T.; Liu, Y. L.; Xiao, Y.; Liang, Y. R.; Electrochim. Acta 2017, $258,504$.

25. Hrapovic, S.; Liu, Y. L.; Male, K. B.; Luong, J. H. T.; Anal. Chem. 2004, 76, 1083.

26. Yang, M. Y.; Yang, Y. H.; Liu, Y. L.; Shen, G. L.; Yu, R. Q.; Biosens. Bioelectron. 2006, 21, 1125.

27. Lakić, M.; Vukadinović, A.; Kalcher, K.; Nikolić, A. S.; Stanković, D. M.; Talanta 2016, 161, 668.

28. Zhou, Y. Y.; Tang, L.; Li, Z.; Liu, Y. Y.; Yang, G. D.; Wu, M. S.; Lei, X. X.; Zeng, G. M.; Environ. Sci. 2013, 34, 1211.

29. Yin, H. S.; Zhang, Q. M.; Zhou, Y. L.; Ma, Q.; Liu, T.; Zhu, L. S.; Ai, S. Y.; Electrochim. Acta 2011, 56, 2748.

30. Paraknowitsch, J. P.; Zhang, J.; Su, D. S.; Thomas, A.; Antonietti, M.; Adv. Mater. 2010, 22, 87.

31. Ma, Z. H.; Wang, H. C.; Yao, X. X.; Liu, M. Q.; Ma, Y. Q.; Chinese J. Anal. Chem. 2015, 43, 1906.

32. Zhang, H.; Li, S.; Zhang, F. H.; Wang, M. X.; Lin, H. X.; J. Solid State Electrochem. 2017, 21, 735.

33. He, J. H.; Xu, Q.; Ding, W. Q.; Li, Q.; Environ. Sci. 2015, 36, 1365.

34. Zhang, Y. Z.; Sun, R. X.; Luo, B. M.; Wang, L. J.; Electrochim. Acta 2015, 156, 228.

35. Wang, X.; Wu, M.; Li, H.; Wang, Q.; He, P.; Fang, Y.; Sens. Actuators, B 2014, 192, 452.

36. Radhakrishnan, S.; Krishnamoorthy, K.; Sekar, C.; Wilson, J.; Kim, S. J.; Chem. Eng. J. 2015, 259, 594.

37. Li, S. J.; Xing, Y.; Deng, D. H.; Shi, M. M.; Guan, P. P.; J. Solid State Electrochem. 2015, 19, 861.

38. Du, J.; Ma, L. L.; Shan, D. L.; Fan, Y. R.; Zhang, L. P.; Wang, L.; Lu, X. Q.; J. Electroanal. Chem. 2014, 722, 38.

39. Wang, G. L.; J. LianYunGang Chem. Tech. 2001, $2,8$.

Submitted: December 20, 2018

Published online: May 30, 2019 